\title{
Dislocation Source and Pile-up in a Twinning-induced Plasticity Steel at High-Cycle Fatigue
}

\author{
Rendong Liu ${ }^{1} \cdot$ Zhiyuan Liang ${ }^{2} \cdot$ Li Lin $^{1} \cdot$ Mingxin Huang ${ }^{3}$
}

Received: 29 September 2020 / Revised: 22 October 2020 / Accepted: 6 November 2020 / Published online: 4 January 2021

(c) The Chinese Society for Metals (CSM) and Springer-Verlag GmbH Germany, part of Springer Nature 2021

\begin{abstract}
Dislocation behaviour of a twinning-induced plasticity (TWIP) steel subjected to high-cycle fatigue tests is investigated in the present study. Grain boundaries are the important sources of dislocation generation during fatigue tests, contributing to the increase in dislocation density. Continuous emission of dislocations from grain boundaries is observed in many grains. Inclusions can sustain large dislocation pile-ups at the inclusion interfaces, leading to a high stress concentration and therefore acting as potential sites of microcrack nucleation. In contrast, annealing twin boundaries are relatively weak boundaries for dislocation pile-ups. When the number of dislocations in a pile-up is large, dislocations can crossover twin boundaries and glide inside the annealing twins. The stress concentration at the twin boundary is relatively low so that twin boundaries could not act as the sites for microcrack initiation.
\end{abstract}

Keywords Dislocation source $\cdot$ Grain boundary $\cdot$ Twin boundary $\cdot$ Fatigue $\cdot$ Inclusion

\section{Introduction}

Twinning-induced plasticity (TWIP) steels have high strength and outstanding ductility, making them potential materials for lightweight structure applications [1-3]. Many studies focused on the strain hardening mechanism of TWIP steels [1, 4-10]. The strain hardening mechanism of TWIP steel is still under debate in the literature. One view considers that dislocation pile-ups at twin boundaries provide strong back-stress and therefore provide "dynamic Hall-Petch" effect and high strain hardening rate [11, 12], which was cited by many researchers [13-17]. However, a recent view considers that deformation twins play a minor role in the strain hardening of TWIP steels, while the high

Zhiyuan Liang

liangzhiyuan@sslab.org.cn

Mingxin Huang

mxhuang@hku.hk

1 Iron and Steel Research Institute, Ansteel Group, Anshan 114021, China

2 Songshan Lake Materials Laboratory, Dongguan 523808, China

3 Department of Mechanical Engineering, The University of Hong Kong, Hong Kong, China dislocation density induced by carbon alloying plays the major role in strain hardening [18-20].

Different to the investigations of strain hardening mechanism of TWIP steels under static tensile tests, studies on fatigue behaviour of TWIP steels are much less [21, 22]. It has been reported that the fatigue limit of TWIP steels is close to the yield strength [21-25]. A TWIP steel subjected to high-cycle fatigue was studied [23], showing that very few deformation twins can be found during fatigue test, different to the static tensile tests. Instead, dislocation cells are found at a stress amplitude lower than the yield stress during fatigue test [23]. Nevertheless, the dislocation sources and dislocation pile-ups during fatigue tests have not been discussed, which are important information for understanding the fatigue behaviour of the TWIP steel. In particular, dislocation pile-ups are the potential sources of microcrack formation during fatigue tests. The present work employs detailed transmission electron microscopy (TEM) characterization to investigate the dislocation sources and the pile-ups at grain boundaries, annealing twin boundaries and inclusions in a TWIP steel subjected to high-cycle fatigue. 


\section{Experimental}

The TWIP steel used in the present study is a hot-rolled product from Ansteel Group, with a nominal chemical composition of $18.5 \% \mathrm{Mn}-0.87 \mathrm{C} \%-0.3 \% \mathrm{Si}-0.2 \% \mathrm{Cr}-$ $0.23 \% \mathrm{Ni}-0.15 \% \mathrm{~V}$ (wt $\%$ ). Smooth dog-bone specimens with a thickness of $18.3 \mathrm{~mm}$ were machined by electrodischarge machining from the as-received steel plate. The sample geometry can be found elsewhere [23]. The large thickness avoids the bulking during tension-compression fatigue tests using an MTS Landmark2 fatigue machine. The high-cycle fatigue test was carried out at a stress amplitude of $300 \mathrm{MPa}$ with a stress ratio of $R=-1$ at room temperature. Under this stress amplitude, fatigue failure of the present TWIP steel takes place at $2 \times 10^{6}$ cycles [23]. In order to investigate the dislocation behaviour before fracture, the fatigue tests were terminated respectively at $10^{4}$ and $10^{6}$ cycles, at which no facture takes place. Transmission electron microscopy (TEM) samples were cut from the fatigue specimen subjected to $10^{4}$ and $10^{6}$ cycles. Standard TEM thin foils were prepared. Twin-jet electro-polishing in a solution of 5\% perchloric acid, $15 \%$ acetic acid and $80 \%$ pure alcohol was carried out at $263 \mathrm{~K}$ for the TEM samples. A TECNAI G2 operated at $200 \mathrm{kV}$ was used for TEM microstructure characterization. Initial microstructure was observed using electron backscattering diffraction (EBSD) carried out in a LEO 1530 machine operated at $20 \mathrm{kV}$ with a scanning step size of $2 \mu \mathrm{m}$.
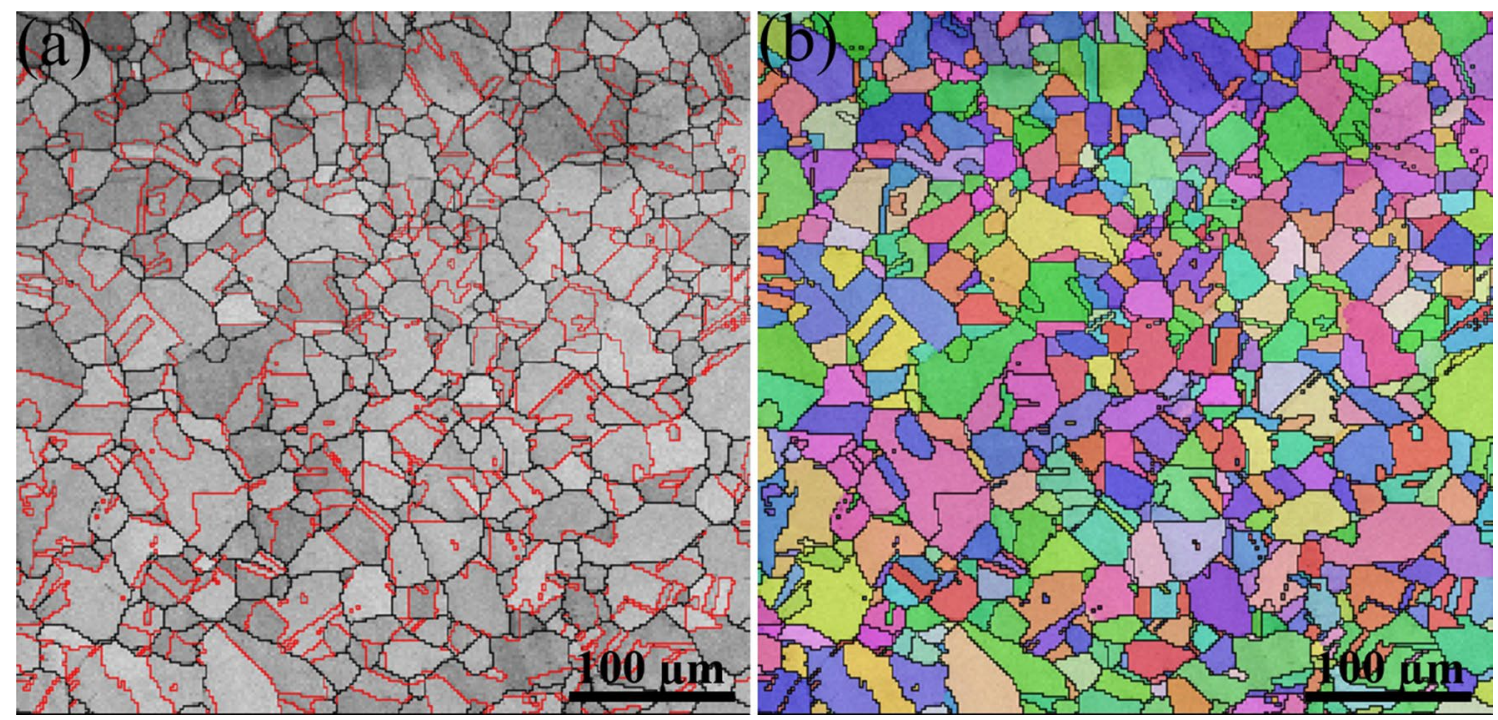

Fig. 1 a EBSD band contrast figure and $\mathbf{b}$ the corresponding inversed pole figure of the initial microstructure of the TWIP steel. Red lines represent the annealing twin boundaries 

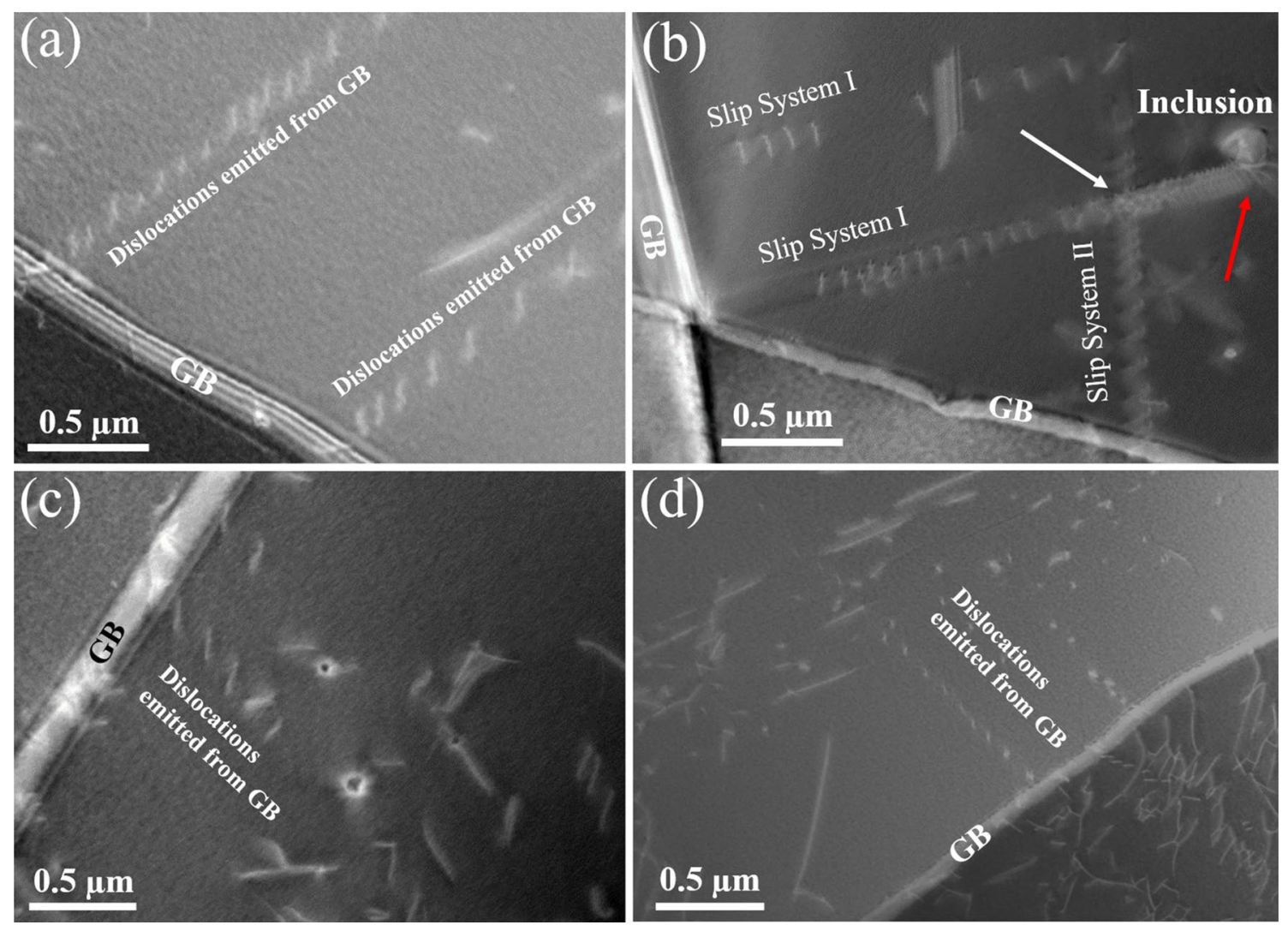

Fig. 2 a Dislocations emitted from two dislocation sources at one grain boundary; b dislocations emitted from different grain boundaries glide at two different slip systems; there is a dislocation pile-up at the interface of the inclusion indicated by the red arrow; c dislocations emitted from one dislocation source; $\mathbf{d}$ dislocations emitted from two dislocation sources at one grain boundary

interaction between dislocations in two different slip systems is also shown in Fig. 2b, indicated by the white arrow. Figure 2c, $\mathrm{d}$ show dislocation sources in some other typical grains.

Figure 3 shows a STEM bright-field image obtained in the fatigue specimen subjected to $10^{4}$ cycles, which shows that dislocations piled up at the boundaries of an annealing twin. It is evident that dislocations can crossover the annealing twin boundaries and glide inside the annealing twins (as indicated by the white arrows (Fig. 3)), even though the number of dislocations in the pile-up is not large. Figure 4 shows STEM dark-field images obtained in the fatigue specimen subjected to $10^{6}$ cycles, which show intensive dislocation tangles and cells in the grain interior. The typical size of dislocation cell is less than $1 \mathrm{um}$. The cell interior is free of dislocations, while the cell walls have a dense dislocation distribution. Dislocation junctions are shown in Fig. 4c.

\section{Discussion}

The initial fully recrystallized microstructure of the present TWIP steel has a very low dislocation density in the order of $10^{11} \mathrm{~m}^{-2}$. It is noted that, under the same fatigue test



Fig. 3 Dislocations piled up at and crossover the annealing twin boundary, indicated by the white arrows 

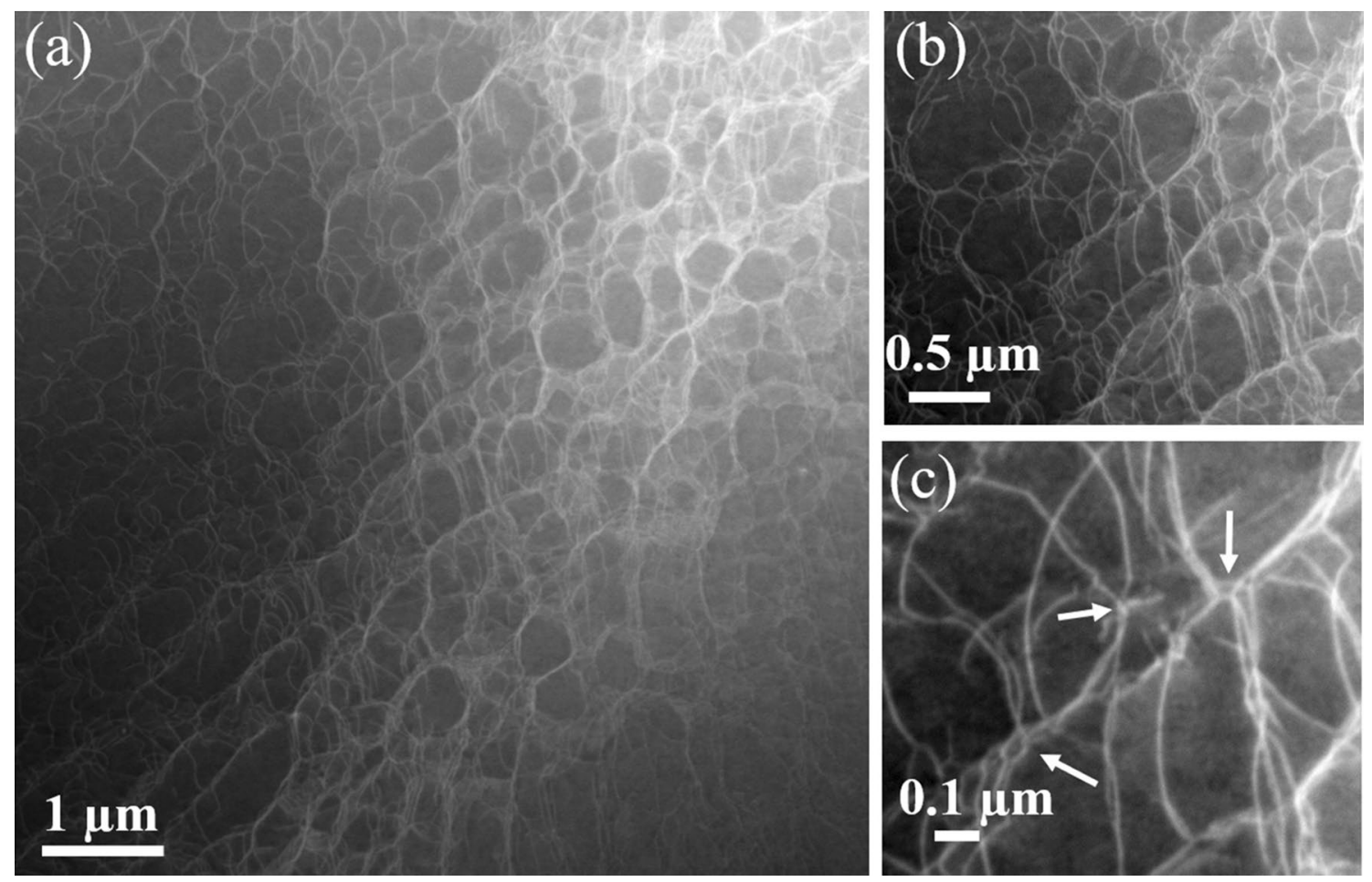

Fig. 4 a Dislocation cells in the grain interior, showing that typical cell size is smaller than one micron, $\mathbf{b}$ an enlarged view of the dislocation cells and $\mathbf{c}$ dislocation junctions indicated by the white arrows

condition, fatigue failure of the present TWIP steel takes place at $2 \times 10^{6}$ cycles [23]. Based on the line counting method [23], the dislocation density of the present TWIP steel after $10^{6}$ cycles reaches a high value of $8.6 \times 10^{13} \mathrm{~m}^{-2}$ [23]. The increase in dislocation density during fatigue tests involves the generation of dislocations from various sources including grain boundaries as well as Frankie-Read sources inside the grain interior. It is very clear that grain boundaries play an important role in the increase in dislocation density. Frankie-Read sources inside the grain interior may also operate, but no direct evidences were observed in the present study. On the contrary, continuous emission of dislocations from grain boundaries is clearly observed in many grains (Fig. 2). If there are no obstacles in front of one particular dislocation source, it could emit dislocations continuously.

It is interesting to note that dislocations emitted from grain boundaries can be terminated by inclusions. The inclusion is so large that dislocations cannot bypass it through the Orowan mechanism, forming dislocation pileups at the inclusion interface as shown in Fig. 2b. If the inclusion is sufficiently small, dislocations may bypass it and form Orowan loops. The very dense dislocations in the pile-up generate a high stress concentration at the inclusion interface, which acts as the potential site for microcrack initiation during fatigue tests. Dislocation tangles could take place at the intersection of two different slip systems as indicated by the white arrow in Fig. 2b. However, such dislocation tangles are not strong enough to stop the gliding of dislocations in the two different slip systems. As a result, no high stress concentration could be formed at such intersections so that they may not act as the nucleation sites for microcrack formation.

It has been reported in nanotwinned $\mathrm{Cu}$ that dislocations can glide through the twin boundaries [26, 27]. It is also true for the present TWIP steel as shown in Fig. 3 . The annealing twin boundaries are relatively weak in terms of the maximum number dislocations piled up at the twin boundary. It is clearly shown that annealing twin boundary cannot sustain a large dislocation pile-up at the twin boundary (Fig. 3), which is different from that at the inclusion interface (Fig. 2b). The stress acting at the leading dislocation of a pile-up is proportional to the number of the dislocations in the pile-up [28]. Therefore, the stress concentration at the twin boundary should be much lower than that at the inclusion interface. It indicates that the annealing twin boundaries shall also not act as the potential sites for microcrack nucleation. It is also noted that very few deformation twins can be found at the current high-cycle fatigue test condition [23]. Therefore, it is very likely that the microcrack initiation of the present TWIP steel under high-cycle fatigue could originate from the inclusions where a high stress concentration is induced by 
the large number of dislocations piled up at the inclusion interface.

\section{Conclusion}

Based on detailed TEM characterization of a TWIP steel subjected to high-cycle fatigue, the following conclusions can be drawn.

1. Grain boundaries are important dislocation sources and play important role in the accumulation of dislocations during fatigue tests.

2. A large number of dislocations piled up at the inclusion interface are the potential location for microcrack nucleation.

3. Dislocations at the front of pile-up can glide through the twin boundary, indicating that twin boundaries cannot sustain a large dislocation pile-up.

\section{References}

[1] O. Bouaziz, H. Zurob, M. Huang, Steel. Res. Int. 84, 937 (2013)

[2] S.G. Lee, B. Kim, M.C. Jo, K.M. Kim, J. Lee, J. Bae, B.J. Lee, S.S. Sohn, S. Lee, J. Mater. Sci. Technol. 50, 21 (2020)

[3] M.C. Jo, J. Yoo, M.C. Jo, A. Zargaran, S.S. Sohn, N.J. Kim, S. Lee, J. Mater. Sci. Technol. 43, 44 (2020)

[4] O. Grässel, L. Krüger, G. Frommeyer, L.W. Meyer, Int. J. Plast. 16, 1391 (2000)

[5] S. Allain, J.P. Chateau, O. Bouaziz, Mater. Sci. Eng. A. 387-389, 143 (2004)

[6] H. Idrissi, K. Renard, L. Ryelandt, D. Schryvers, P.J. Jacques, Acta Mater. 58, 2464 (2010)
[7] S.J. Lee, J. Kim, S.N. Kane, B.C.D. Cooman, Acta Mater. 59, $6809(2011)$

[8] B.C. De Cooman, Y. Estrin, S.K. Kim, Acta Mater. 142, 283 (2018)

[9] X.J. Wang, X.J. Sun, C. Song, H. Chen, S. Tong, W. Han, F. Pan, Acta Metall. Sin. -Engl. Lett. 32, 746 (2019)

[10] W. Song, T. Ingendahl, W. Bleck, Acta Metall. Sin. -Engl. Lett. 27, 546 (2014)

[11] O. Bouaziz, S. Allain, C. Scott, Scr. Mater. 58, 484 (2008)

[12] O. Bouaziz, Scr. Mater. 66, 982 (2012)

[13] Y. Wei, Y. Li, L. Zhu, Y. Liu, X. Lei, G. Wang, Y. Wu, Z. Mi, J. Liu, H. Wang, H. Gao, Nat. Commun. 5, 3580 (2014)

[14] B. Gludovatz, A. Hohenwarter, D. Catoor, E.H. Chang, E.P. George, R.O. Ritchie, Science 345, 1153 (2014)

[15] Z. Li, K.G. Pradeep, Y. Deng, D. Raabe, C.C. Tasan, Nature 534, 227 (2016)

[16] Z. Zhang, M.M. Mao, J. Wang, B. Gludovatz, Z. Zhang, S.X. Mao, E.P. George, Q. Yu, R.O. Ritchie, Nat. Commun. 6, 10143 (2015)

[17] Z. Zhang, H. Sheng, Z. Wang, B. Gludovatz, Z. Zhang, E.P. George, Q. Yu, S.X. Mao, R.O. Ritchie, Nat. Commun. 8, 14390 (2017)

[18] Z.Y. Liang, Y.Z. Li, M.X. Huang, Scr. Mater. 112, 28 (2016)

[19] Z.C. Luo, M.X. Huang, Scr. Mater. 142, 28 (2018)

[20] Z.C. Luo, M.X. Huang, Scr. Mater. 178, 264 (2020)

[21] A.S. Hamada, L.P. Karjalainen, J. Puustinen, Mater. Sci. Eng. A 517, 68 (2009)

[22] T. Niendorf, C. Lotze, D. Canadinc, A. Frehn, H.J. Maier, Mater. Sci. Eng. A. 499, 518 (2009)

[23] X. Wang, Z.Y. Liang, R.D. Liu, M.X. Huang, Mater. Sci. Eng. A. 647, 249 (2015)

[24] A.S. Hamada, L.P. Karjalainen, A. Ferraiuolo, J. Gil Sevillano, F. de las Cuevas, G. Pratolongo, M. Reis, Metall. Mater. Trans. A. 41, 1102 (2010)

[25] A.S. Hamada, L.P. Karjalainen, Mater. Sci. Eng. A. 527, 5715 (2010)

[26] Y.T. Zhu, X.Z. Liao, X.L. Wu, Prog. Mater Sci. 57, 1 (2012)

[27] K. Lu, L. Lu, S. Suresh, Science 324, 349 (2009)

[28] J.P. Hirth, J. Lothe, Theory of Dislocation (Wiley, New York, 1982). 